progesterone in the blood serum is found in the women of reproductive age. According to the literature, progesterone has a close relationship with T-cell immunity. A value of T-cell deficiency plays an important role in the cause of the autoimmune process

Objectives: To study of progesterone correction in RA patients. The aim of this study was to evaluate the effectiveness of progesterone deficiency correction in patients with rheumatoid arthritis based on the analysis of articular syndrome Methods: The study involved 40 patients with a documented diagnosis of RA, women of reproductive age. The study group consisted of 30 patients who had correction of progesterone deficiency background in the pathogenetic therapy. The control group consisted of 10 female patients who are on the pathogenetic therapy. We used the following criteria: disease activity and severity of the articular syndrome with determining of the number of tender and swollen joints, indices of DAS and HAQ. Statistical analysis of the results of research used the method of parametrics of Student criterion

Results: Among the patients studied disease duration ranged from 3 months to 19 years (mean age $10 \pm 7,2$ years), 20 patients $(50 \%)$, from 5 to 10 years - $15(37.5 \%)$, and more than 10 years - 5 patients $(12.5 \%)$. X-ray picture of joint damage in the majority of patients corresponded to stage $2-3-87.5 \%$ (35 patients). Less common muscular disorders $(7.5 \%)$, mainly in patients taking long-term GC, myalgia and muscle malnutrition were detected in $7.5 \%$ and $25 \%$ of patients, respectively. In addition to the articular syndrome, the most frequent complaints of general weakness $(75 \%)$, irritability, sleep disorders and attention $(50 \%)$, anxiety and anxiety $(75 \%)$, low-grade temperature $(10 \%)$

Conclusions: Progesterone deficiency correction in RA patients against pathogenic therapy has improved performance of articular syndrome and improves quality of life, such as vitality, general health and social function as well as it contributes to the positive dynamics of mental health

References:

[1] McInnes IB, Schett G. The pathogenesis of rheumatoid arthritis New Engl. J. Med. 2011;365:2205-19.

[2] Wells G et al. Validation of the 28-joint Disease Activity Score (DAS28) and European League Against Rheumatism response criteria based on C-reactive protein against disease progression in patients with rheumatoid arthritis, and comparison with the DAS28 based on erythrocyte sedimentation rate. Ann. Rheum. Dis. 2009;68:954-60.

[3] Ware JE, Sherbourne CD. The MOS 36-Item short-form health survey. Med. Care. Med Care. 1992;30(6):473-83.

Disclosure of Interest: None declared

DOI: 10.1136/annrheumdis-2017-eular.1306

\section{AB1213-HPR A NATIONAL RHEUMATOID ARTHRITIS REGISTRY SUPPORTED BY A PUBLIC POLICY AS A STRATEGY FOR DISEASE CONTROL AND RISK MANAGEMENT IN COLOMBIA}

O. Valencia ${ }^{1}$, P. Sánchez ${ }^{1}$, L. Acuña ${ }^{1}$, L. Soler ${ }^{1}$, C.E. Toro ${ }^{2} .{ }^{1}$ Cuenta de Alto Costo; ${ }^{2}$ Asociación Colombiana de Reumatología, Bogotá, Colombia

Background: Rheumatoid arthritis (RA) is a chronic disease that implies high direct and indirect costs for the health system $(1,2)$. According to the needs of the health care system, the clinical interests and the national regulatory framework, it was developed a national registry information of RA patients (3).

Objectives: To show how a registry of information that would meet the RA situation was developed and to present the results obtained from the analysis of the Registry on this first year.

Methods: A national RA Registry was created after a comprehensive literature review to identify the relevant variables to determine monitoring indicators used by health insurers and health services providers in the attention of patients with RA. Variables were selected and defined by an agreement with clinical experts, thematic and methodological experts and were evaluated by the Ministry of Health in order to review and approve the structure to gather the information.

Results: A structure of 89 variables contained was defined. All entities must report annually to the Registry all the patients with a diagnosis of RA, their clinical and demographic characteristics, and the process of care and costs (3). On its first year the Registry provided a baseline of the disease situation of 68.357 patients with RA. Prevalence, incidence, state of disease and drugs including synthetic and biologic DMARDs were analyzed (Table 1). Most important results were: mean age 57 years; relation women: men 5.2:1; age at onset of disease: 36 years, mean evolution time of disease: 7 years; population with DAS 28 measured 45.6\%; mean DAS-28 2.8; percentage of the patient with DMARD therapy $78.9 \%$ and bDMARD $16.5 \%$.

Table 1. Characteristics of the population

\begin{tabular}{lccccc}
\hline Variable & Obs & Mean/prop. & Std. Dev. & Min & Max \\
\hline Age & 68376 & 57.0 & 13.3 & 22 & 104 \\
Age at onset of disease & 13607 & 36.4 & 7.7 & 20 & 51 \\
Evolution time of RA & 37963 & 7.5 & 8.1 & 0 & 51 \\
DAS28 & 30956 & 2.82 & 1.37 & 0 & 1 \\
"Women & 57461 & 84.04 & & & \\
"Men & 10914 & 15.96 & & & \\
"bDMARD & 11276 & 16.50 & & & \\
"DMARD & 53374 & 78.01 & & & \\
\hline
\end{tabular}

Conclusions: A national Registry supported by an official policy, with data from the real world provided for healthcare insurers gives an opportunity to obtain a global vision and to identify failures and strengths in the attention process of $\mathrm{RA}$, and to develop indicators to obtain better outcomes. In the future, through continuous efforts towards improving the quality of care provided, these will allow to monitoring and decreasing the burden of RA in the country and may serve as a model to other countries.

References:

[1] Muñetón GA, Quintana G. La epidemiología de la artritis reumatoide. Rev Colomb Reumatol. 2015 Sep [cited 2016 Jul 25];22(3):145-7. Available from: http://www.elsevier.es/es-revista-revista-colombiana-reumatologia-374articulo-la-epidemiologia-artritis-reumatoide-S0121812315000845.

[2] Quintana G., Restrepo JP, Cáceres H, Rueda JD. Economic evaluation of the treatment of rheumatoid arthritis with anti-TNF biological therapy in Colombia. Acta Médica Colomb. 2011;36(1):24-9. Available from: http://www.scielo.org.co/pdf/amc/v36n1/v36n1a05.pdf.

[3] MSPS. Resolucion No. 1393. 2015. p. 14.

Disclosure of Interest: None declared

DOI: 10.1136/annrheumdis-2017-eular.5017

\section{AB1214-HPR SPINAL BRUCELLOSIS: A RETROSPECTIVE STUDY OF 30 CASES}

S. Rekik, S. Boussaid, I. Abdelkafi, S. Hela, I. Cheour, M. Elleuch. Rheumatology, la Rabta, Tunis, Tunisia

Background: Brucellosis is a major health problem in Mediterranean countries including Tunisia. The clinical presentation of this zoonosis varies considerable but osteoarticular involvement and spinal brucellosis particulary is the commonest complication.

Methods: This study was carried out between 2000 and 2015. One hundred and six patients with infectious spondylodicitis hospitalized in the department of rheumatology were analyzed. All patients were thoroughly interrogated subjected to a rigorous clinical examination and a battery of investigations including: complete blood count, urine analysis, blood culture, erythrocyte sedimentation rate, $\mathrm{C}$ - reactive protein (CRP) and serology for brucellosis. The imaging of spine ordered including: X-ray, bone scan and magnetic resonance imaging (MRI) with contrast enhancement.

Results: Thirty of the 106 patients $(28 \%)$ proved to have spinal brucellosis. The mean age of these patients was 53 years (range 15-68 years) and female/men ratio at 1.5 . The mean delay of diagnosis was 8 months. The following symptoms were observed: fever in 14 patients and back pain in all of patients. Other symptoms were less frequently observed, such as splenomegaly (2 patients), peripheral adenopathy ( 5 patients) and diarrhea (2 patients). Laboratory exams showed elevated erythrocyte sedimentation rate in 13 patients, high levels of CRP in all patients and leukocytosis in 11 cases. Wright serology was positive in 21 of the patients. Brucella melitensis was isolated in blood cultures in 2 cases. Standard X-rays were performed in all patients. They showed signs of spondylodiscitis in the lumbar spine in 20 cases, cervical in 2 cases and dorsal in 8 cases. Ct-scan and MRI confirms the diagnosis and showed associated epiduritis in 2 cases or abscess in 6 cases. Bone biopsy with histopathological examination was performed in 7 cases. A combination of cycline and rifampicin was given to all patients. The duration of therapy was between 6 and 8 weeks.

Conclusions: Brucellosis is present with various clinical signs in endemic areas and may simulate many diseases. The need for prompt diagnosis and treatment of spinal brucellosis is of utmost importance to prevent serious bone destruction and severe neurologic Sequelae.

Disclosure of Interest: None declared

DOI: 10.1136/annrheumdis-2017-eular.6301

\section{HPR interventions (educational, physical, social and psychological)}

\section{AB1215-HPR EFFECTS OF BEETROOT JUICE SUPPLEMENTATION N ENDOTHELIAL FUNCTION AND MARKERS OF INFLAMMATION AMONG PATIENTS WITH RHEUMATOID ARTHRITIS}

A. Stavropoulos ${ }^{1}$, E. Manthou ${ }^{2}$, T. Nakopoulou ${ }^{3}$, K. Georgakouli ${ }^{2}$, A. Jamurtas ${ }^{2} .{ }^{1}$ Carnegie School of Sport, Leeds Beckett University, Leeds, United Kingdom; ${ }^{2}$ School of Physical Education and Sports Science, University of Thessaly; ${ }^{3}$ Radiology, General Hospital of Trikala, Trikala, Greece

Background: Nitric oxide (NO) is central in the process of vasodilatation (1). Limited bioavailability of NO often associates with endothelial dysfunction, a precursor to atherogenesis (1). Such dysfunction is often observed in patients with chronic conditions such as Rheumatoid Arthritis (RA) (2) and Chronic Obstructive Pulmonary Disease (COPD) (3). Common therapies for this include the administration of nitrate-rich medication. However, in the general population beetroot juice supplementation has been shown to increase NO bioavailability (4). It could therefore have beneficial effects on endothelial function of these patients as well. 
Objectives: To evaluate the effects of short-term beetroot juice supplementation on endothelial function in patients with RA and COPD.

Methods: A total of 28 patients, 9 with RA, 9 with COPD and 10 healthy controls participated in the study. Following consent, they were asked to report at the testing venue (Ultrasonography Laboratory, General Hospital of Trikala) early in the morning, following an overnight fast. Demographic and disease characteristics were recorded; height, weight, classical risk factor for cardiovascular disease and body composition were assessed. Endothelial function was assessed using flow mediated vasodilatation. They randomly received either beetroot (experimental leg) or blackcurrant juice (control leg), which they consumed daily for two weeks. Thereafter they were re-evaluated. Following a two-week washout period, they crossed over to the other leg of the study.

Results: There was no difference in pre-occlusion diameter between any of the time-points. Endothelial function was significantly improved following beetroot juice consumption for both patient groups (RA: $2.6 \%$ [0.9 - 6.2] vs $10.7 \%$ [6.2 11.7]; $p=0.013$. COPD: $3.4 \%[1.2-4.8]$ vs $7.8 \%$ [3.6 - 10.2]; $p=0.034$ ) while it remained relatively unaffected by blackcurrant consumption (Overall: $3.9 \%$ [0 $5.1]$ vs $4.2 \%[2.3-6.1] ; p=0.26)$.
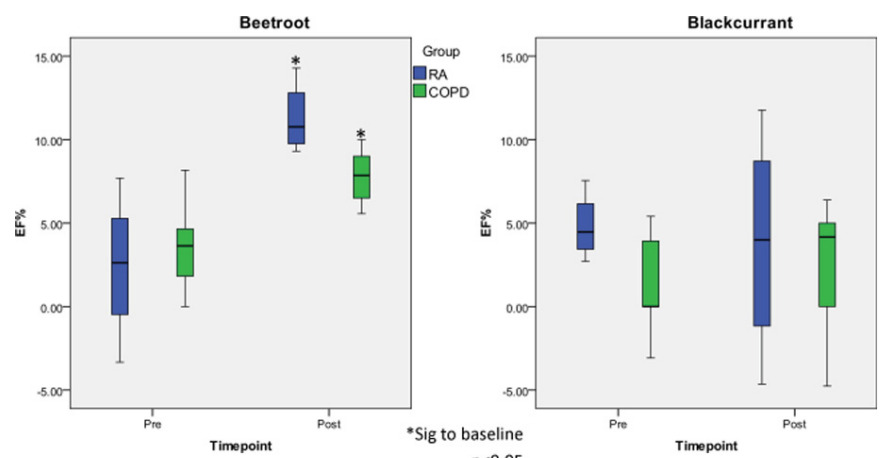

Figure 1

Conclusions: A two week consumption of beetroot juice seems to be able to improve endothelial function among patients with RA and COPD. This could elicit significant health benefits. Further research to investigate the benefits of longer-term use on endothelial function and related cardiovascular health, as well as disease symptoms, and quality of life is advocated.

References:

[1] Moncada, S. and Higgs, E.A. The discovery of nitric oxide and its role in vascular biology. British Journal of Pharmacology 2006, 147: S193-S201.

[2] Sandoo, A. et al. Vascular function and morphology in rheumatoid arthritis: a systematic review. Rheumatology 2011, 50 (11): 2125-2139.

[3] Clarenbach, C.F. Determinants of endothelial function in patients with COPD. European Respiratory Journal 2013, 42 (5): 1194-1204.

[4] Clifford, T. et al. The Potential Benefits of Red Beetroot Supplementation in Health and Disease. Nutrients 2015, 7.4: 2801-2822.

Disclosure of Interest: None declared

DOI: 10.1136/annrheumdis-2017-eular.4519

\section{AB1216-HPR THE EFFECTS OF APPLICATION OF IONTOPHORESIS AND PHONOPHORESIS IN PATIENTS WITH SUBACROMIAL IMPINGEMENT SYNDROME}

A. Yildiz ${ }^{1}$, E. Kusan ${ }^{2} .{ }^{1}$ Physiotherapy and Rehabilitation, Marmara University Health Sciences Faculty; ${ }^{2}$ Physiotherapy and Rehabilitation, Kosuyolu Medipol Hospital, Istanbul, Turkey

Background: Subacromial impingement syndrome (SIS) is defined as the mechanical compression of subacromial structures between the coraco-acromial arch and the humerus during active elevation of the arm above shoulder height. Objectives: The aim of the study was to investigate the effects of applications of iontophoresis and phonophoresis, which has been used in addition to physiotherapy program on pain and disability level in patients with SIS.

Methods: The study was conducted with subjects $(n=43)$ diagnosed with SIS. The subjects were divided into two groups randomly as iontophoresis group (IG) and phonophoresis group (PG). Diclofenac sodium iontophoresis was applied to the first group $(n=22)$, diclofenac sodium phonophoresis was applied to the second group $(n=21)$. In addition all of groups therapy program includes superficial heat, transcutaneous electrical nerve stimulation and exercise. The groups were evaluated before and after treatment in terms of pain and scores of shoulder disability. Visual analog scale was used to assess of pain (night pain, rest pain, pain with motion and pain in functional use), Shoulder Disability Questionnaire (SDQ) and Disabilities of the Arm Shoulder and Hand (DASH) were used to assess of shoulder disability.

Results: 43 patients with IS aged 18 to 65 years were recruited to the study. Demographic data were similar in the groups.

After treatments pain severity (night pain and pain in functional use) was significantly decreased in both groups $(p<0,05)$ and in the scores of disability of shoulder $(p<0,05)$ in both groups. Pain relief was similar in groups. SDQ and
Table 1. The level of pain, functionality and disability scores in groups

\begin{tabular}{|c|c|c|c|c|c|c|}
\hline & \multicolumn{2}{|c|}{ IG } & \multirow[t]{2}{*}{$\mathrm{p}$} & \multicolumn{2}{|c|}{$P G$} & \multirow[t]{2}{*}{$\mathrm{p}$} \\
\hline & $\begin{array}{c}\text { Before } \\
\text { mean } \pm \mathrm{sd}\end{array}$ & $\begin{array}{c}\text { After } \\
\text { mean } \pm \text { sd }\end{array}$ & & $\begin{array}{c}\text { Before } \\
\text { mean } \pm \mathrm{sd}\end{array}$ & $\begin{array}{c}\text { After } \\
\text { mean } \pm \text { sd }\end{array}$ & \\
\hline Night pain severity & $5,59 \pm 3,01$ & $1,77 \pm 1,99$ & * & $4,47 \pm 2,42$ & $1,42 \pm 1,8$ & * \\
\hline Severity of general pain & $5,09 \pm 2,13$ & $2,63 \pm 1,59$ & * & $4,52 \pm 1,72$ & $2,28 \pm 1,45$ & * \\
\hline SDQ & $48,00 \pm 20,75$ & $22,36 \pm 20,41$ & * & $50,12 \pm 21,18$ & $19,35 \pm 15,84$ & * \\
\hline DASH & $38,90 \pm 14,74$ & $19,63 \pm 9,37$ & * & $41,57 \pm 9,53$ & $22,64 \pm 10,37$ & * \\
\hline
\end{tabular}

IG: Iontophoresis group, PG: Phonophoresis group. ${ }^{*} \mathrm{p}<0,001$

DASH scores were improved in two groups after treatments. But there was no difference between the groups in terms of functionality and disability scores.

Conclusions: This study shows that diclofenac sodium iontophoresis and phonophorosis that are used in patients with subacromial impingement syndrome have similar positive therapeutic effects on shoulder functions.

References:

[1] Kuhn JE. Exercise in the treatment of rotator cuff impingement: a systematic review and a synthesized evidence-based rehabilitation protocol. J Shoulder Elbow Surg. 2009 Apr;18(1):138-60.

[2] Sedeek SM et al. Subacromial impingement syndrome: review article. Hard Tissue 2013 Sep 28;2(4):39-43.

[3] Ozsahin M et al. Adaptation of the Shoulder Disability Questionnaire to the Turkish population, its reliability and validity. International Journal of Rehabilitation Research. 2008:31(3):241-45.

[4] Düger et al. Kol, omuz ve el sorunları anketi (Disabilities of the Arm, Shoulder and Hand - DASH) Türkçe uyarlamasının güvenirliği ve geçerliği. Fiyoter Rehabil. 2006;17(3):99-107.

Disclosure of Interest: None declared

DOI: 10.1136/annrheumdis-2017-eular.4883

\section{AB1217-HPR THE EFFCET OF ADDING WII FIT ${ }^{\circledR}$ GAMES TO TRADITIONAL REHABILITATION ON PAIN, QUALITY OF LIFE AND FUNCTIONALITY AFTER ACL RECONSTRUCTION}

Z.B. Karakoç, T. Kuru Çolak, B. Kapssigay, Z. Sarı, M.G. Polat. Physical Therapy and Rehabilitation, Marmara University Health Science Institute, Istanbul, Turkey

Background: Wii Fit ${ }^{\circledR}$ games are widely used in the rehabilitation field due to their audiovisual feedback and motivating effect (1). Although it is well known that Wii $\mathrm{Fit}^{\circledR}$ games improve the quality of life in various groups $(2,3)$, there is no study on those who have undergone anterior cruciate ligament (ACL) arthroscopic surgery. Objectives: The aim of this study was to determine the effect of Wii Fit ${ }^{\circledR}$ games on pain, quality of life and lower extremity functionality after ACL reconstruction. Methods: Patients who underwent arthroscopic ACL reconstruction surgery in Kartal Dr. Lutfi Kırdar Training and Research Hospital were included in this study. Being volunteer for this study, not receiving any other treatment after surgery and being in the first 6 months after surgery were determined as inclusion criteria. Having any orthopaedic injury or congenital deformitiy and having vision, balance or neurologic problems were defined as exclusion criteria. After recording demographic data patients' pain, quality of life and lower extremity functionality were evaluated with "Visual Analog Scale (VAS)", Anterior Cruciate Ligament Quality of Life (ACL-QoL) Scale and "Lower Extremity Functionality Scale (LEFS)", respectively.

Patients received accelerated rehabilitation program 3 days per week, for 6 weeks. Wii $\mathrm{Fit}^{\circledR}$ games has added to accelerated program for 40 minutes in every treatment sessions in the last three weeks. Assessments were performed the baseline 3th week and, end of the treatment. The SPSS v11.5 was used for data analysis.

Results: Twelve males with a mean age of $29 \pm 8,51$ years were included in this study. Their average body mass index, time between injury and surgery and time between surgery and the beginning of rehabilitation were $25,82 \pm 2,85 \mathrm{~kg} / \mathrm{m}^{2}$, 374 days and $30 \pm 42,62$ days, each seperately. Pain improved significantly during the treatment $(\mathrm{p}=0.012)$. The quality of life level increased significantly at the end of the study compared to the 3 th assessment $(p=0.041)$. Lower extremity functionality improved during the rehabilitation $(p=0.003)$.

Conclusions: Patients participating in this study expressed $\mathrm{Wii} \mathrm{Fit}^{\circledR}$ games as funny and easy method to utilize. Wii $\mathrm{Fit}^{\circledR}$ games are suitable for use in patients who have had ACL arthroscopic surgery.

\section{References:}

[1] Minyoung L, Dongwon S, Jaebum S, Jungjin K, Seon-Deok E, BumChul Y. Patient perspectives on virtual reality-based rehabilitation after knee surgery: importance of level of difficulty. Journal of Rehabilitation Research and Development. 2016; 53 (2): 239-52.

[2] Hammond, J., Jones, V., Hill, EL., Green, D., Male, I. An investigation of the impact of regular use of the Wii Fit to improve motor and psychosocial outcomes in children with movement difficulties: a pilot study. Child: care, health and development. 2014; 40 (2): 165-175.

[3] Plow, M., Finlayson, M. Potential benefits of Nintendo Wii Fit among people with multiple sclerosis: a longitudinal pilot study. International journal of MS care. $2011 ; 13(1): 21-30$

Disclosure of Interest: None declared

DOI: 10.1136/annrheumdis-2017-eular.6105 